\title{
Comunicação
}

[Communication]

\section{Perfil dos cães sororreagentes para aglutininas anti-Leptospira interrogans em Belo Horizonte, Minas Gerais, 2001/2002}

\author{
[Serological profile of seropositive dogs to anti-Leptospira interrogans agglutinins in \\ Belo Horizonte, Minas Gerais, Brazil, 2001-2002] \\ D.F. Magalhães ${ }^{1}$, J.A. Silva ${ }^{1}$, E.C. Moreira ${ }^{1}$, V.M.L. Wilke ${ }^{2}$, \\ A.B.V. Nunes ${ }^{3}$, J.P.A. Haddad ${ }^{1}$, J.N.C. Meneses ${ }^{1}$ \\ ${ }^{1}$ Escola de Veterinária - UFMG \\ Caixa Postal 567 \\ 30123-970 - Belo Horizonte, MG \\ ${ }^{2}$ Centro de Controle de Zoonoses - PBH -Belo Horizonte, MG \\ ${ }^{3}$ Médica veterinária autônoma
}

Leptospirose é doença infectocontagiosa de grande repercussão na saúde pública, devido a sua facilidade de transmissão, a alta morbidade, apesar da baixa mortalidade, e a relação direta com as condições socioeconômicas da população. Entre os animais domésticos, em ambiente urbano, os cães são a principal fonte de infecção para o homem, pois vivem em contato direto com as pessoas e podem eliminar leptospiras vivas na urina durante meses, mesmo sem apresentar sinais clínicos. A prevalência de sororreagentes em populações caninas no Brasil varia entre 13,1 e 27,3\% (Magalhães et al., 2006; Aguiar et al., 2007), e as sorovariedades encontradas têm sido relacionadas com o meio ambiente e as espécies que coabitam com os cães.

O objetivo deste estudo foi determinar o perfil, em relação à raça, ao sexo, à idade e ao tipo de apreensão, dos cães positivos para diferentes sorovariedades de Leptospira interrogans em Belo Horizonte.

O trabalho foi desenvolvido no município de Belo Horizonte, nas nove regionais administrativas da Prefeitura Municipal, de setembro de 2001 a setembro de 2002. A prevalência de cães sororreagentes para as sorovariedades de Leptospira interrogans foi estimada utilizando-se o valor 0,032 de prevalência esperada, de acordo com Santa Rosa et al. (1974), que verificaram, em Belo Horizonte, 5,9\% de cães reagentes, sendo 3,2\% positivos para Icterohaemorragiae. Aplicou-se a fórmula para estudo de prevalência por amostragem do Centro Panamericano de Zoonoses (Procedimientos..., 1979), adotando-se 95\% como grau de confiança e um erro amostral de $18 \%$, obtendo-se, assim, uma amostra de 3191 cães. Para se obter uma amostra proporcional de cada distrito sanitário, utilizou-se como base o censo canino do ano de 2000. Os cães foram recolhidos pelo Centro de Controle de Zoonoses de Belo Horizonte, para cada animal foi preenchida uma ficha com o endereço, e as variáveis: sexo, idade, raça e tipo de apreensão. De acordo com a forma de apreensão, os animais foram classificados como cães de captura, ou seja, animais recolhidos pela "carrocinha" - sem endereço ( $n=2625)$; e de busca domiciliar - com endereço completo $(n=875)$, ambos sem histórico de vacinações contra leptospirose.

As amostras foram processadas pela técnica de soroaglutinação microscópica (SAM) descrita por RYU (1970), utilizando-se antígenos vivos de leptospiras com cinco a sete dias de cultura, em meio líquido de Ellinghausen. As sorovariedades utilizadas foram Canicola, Icterohaemorrhagiae, Pomona, Ballum, Pyrogenes, Autumnalis, Australis e Tarassovi. A 
reação de SAM foi positiva quando ocorreu, no mínimo, 50\% de aglutinação, em diluições iguais ou superiores a 1:200.

O banco de dados foi organizado utilizando-se o programa Epi-info versão 6.02 (Dean et al., 1995). As diferenças de freqüências entre as variáveis raça, sexo, idade e tipo de apreensão foram analisadas pelo teste do $\chi^{2}$ descrito por Sampaio (1998), fixando-se o nível de significância em $(\mathrm{P}<0,05)$ e processando as estatísticas na planilha eletrônica Excel versão 97. Para obtenção das Odds Ratio dos diferentes fatores de risco foram utilizados modelos de regressão logística descritos por Dohoo et al. (2003).

Foram processadas 3417 amostras de soros, sendo 828 de cães de busca domiciliar e 2589 de cães de captura. Em $448 \quad(13,1 \%)$ foram observadas reações positivas à SAM, para uma ou mais sorovariedades de L. interrogans, com títulos que variaram de 200 a 25.600 . As maiores freqüências de reações positivas foram para as sorovariedades Canicola (7,0\%), Ballum (6,1\%), Pyrogenes $(3,2 \%)$ e Icterohaemorrhagiae $(2,9 \%)$, as demais apresentaram freqüência inferior a 1,0\%. Caldas e Dória (1976); Ávila et al. (1980); Modolo et al. (1999), também relataram a sorovariedade Canicola como a mais prevalente no cão. Essa sorovariedade, conforme citado por Hagiwara et al. (2004), tem no cão seu hospedeiro natural, o que desencadeia um quadro clínico brando, porém com um quadro acentuado de leptospiúria. Dessa forma, o cão pode se manter como portador durante vários meses, sendo importante fonte de infecção para o homem. A segunda sorovariedade mais encontrada foi a Ballum, o que também foi verificado por Ávila et al. (1980) em Jaboticabal, SP. Os camundongos (Mus musculus), hospedeiros naturais dessa sorovariedade, possuem hábito intradomiciliar e costumam fazer seus ninhos no interior de garagens, quintais, armários e depósitos de ração, o que facilita a contaminação dos cães pelo contato com a urina desses roedores. Além do camundongo, o rato de esgoto (Rattus norvegicus) também pode ser importante fonte de contaminação para o cão, sendo responsável pela transmissão dessa sorovariedade. Outra sorovariedade transmitida por meio da urina do rato de esgoto e que tem nele seu hospedeiro natural é a Icterohaemorrhagiae, que diferente do encontrado por Santa Rosa et al. (1974) em Belo Horizonte, Hagiwara e Santa Rosa (1975) em São Paulo, e Lilembaum et al. (2000) em Oriximina, PA como a primeira sorovariedade mais freqüente, foi a quarta em prevalência no presente estudo. Provavelmente, em Belo Horizonte, houve maior contato dos cães com camundongos em relação a outros roedores, pois existem evidências de uma tendência crescente da manutenção do cão dentro do domicílio.

Na Fig. 1, observa-se a distribuição dos cães positivos de acordo com o sexo. A prevalência de machos positivos $(15,0 \%)$ foi maior que a de fêmeas $(10,8 \%)$, o que também foi verificado por Modolo et al. (1999) em Botucatu, Rosseti et al. (1999) em Buenos Aires e Aguiar et al. (2007) em Rondônia. Os machos são mais acometidos, principalmente cães de rua quando as fêmeas entram no cio, onde a possibilidade de se infectar com leptospiras presentes na urina de uma cadela portadora renal é um risco real. A Odds Ratio para a variável sexo indica que o macho tem 1,45 vezes mais chance de ter infecção por $L$. interrogans.

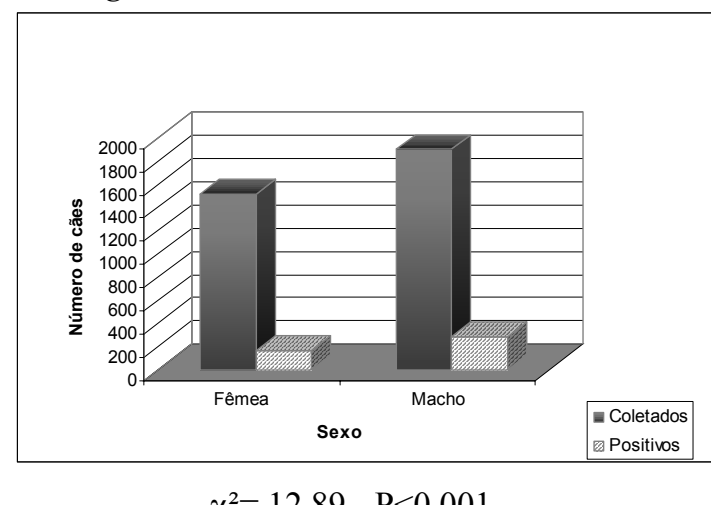

$$
\chi^{2}=12,89-\mathrm{P}<0,001 .
$$

Figura 1. Distribuição dos cães testados e reagentes para aglutininas anti-Leptospira interrogans de acordo com o sexo, Belo Horizonte, MG, 2001/2002.

Em relação à idade, não houve diferença entre os cães positivos maiores e menores de um ano $(\mathrm{P}=$ 0,078), o que também foi observado por Modolo et al. (1999). A ausência de diferença significativa entre cães acima de um ano $(13,1 \%)$ e abaixo de um ano $(15,4 \%)$ pode ter ocorrido pelo fato de os cães recolhidos pelo $\mathrm{CCZ}-\mathrm{BH}$ serem, na grande maioria, adultos e, conseqüentemente, a maior parte das amostras sangüíneas terem sido oriundas desses cães. Reis et al. (1972) em Belo Horizonte, e Aguiar et al. (2007) em Rondônia, encontraram maior 
freqüência em cães adultos. Verifica-se que, quanto maior a idade, maiores são as possibilidades de um cão adulto ser infectado (Rosseti et al., 1999; Aguiar et. al., 2007).

A Fig. 2 apresenta a distribuição dos positivos entre animais com e sem raça definida. Houve diferença significativa $(\mathrm{P}<0,05)$ entre $\mathrm{O}$ percentual de positivos nos cães sem raça definida $(14,1 \%)$ e naqueles com raça definida $(7,9 \%)$. Resultados semelhantes foram relatados por Caldas e Dória (1976) e Modolo et al. (1999). Pode-se inferir que a maioria dos cães vadios não tem raça definida e por viver nas ruas, provavelmente, está mais exposta aos fatores de risco da infecção, além de não ter tido a oportunidade de ser protegida por meio da vacinação. A Odds Ratio para a variável raça mostra que não ter raça definida, aumenta em 1,89 vezes a chance de o cão ter infecção por $L$. interrogans.

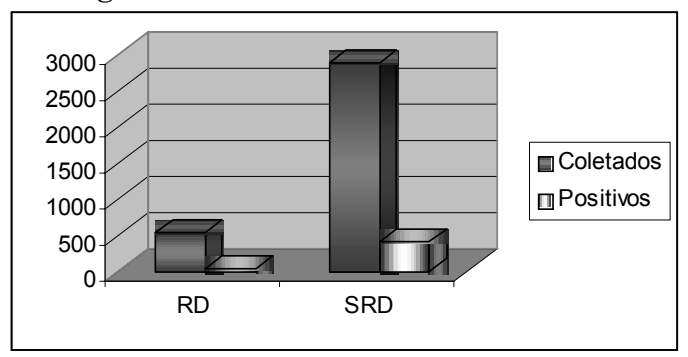

$$
\chi^{2}=14,83-\mathrm{P}<0,001
$$

Figura 2. Distribuição dos cães testados e reagentes para aglutininas anti-Leptospira interrogans em relação a raça, Belo Horizonte, MG, 2001/2002.

A análise, pela regressão logística, da interação entre as variáveis, tipo de apreensão, raça e sexo mostra que existe uma associação entre as variáveis raça e sexo e entre tipo de apreensão e raça. $\mathrm{O}$ fato de o animal ser fêmea, como já foi mencionado anteriormente, faz com que ocorra certa proteção ao risco de adquirir a infecção, e quando essa variável interage com a variável raça, o fato de ser fêmea e de raça definida aumenta ainda mais a proteção ao fator doença. Ser macho acarreta um risco 1,45 vezes maior de ter a infecção, e ser macho sem raça definida aumenta o risco. Esse animal tem 1,74 vezes mais chance de adquirir a infecção que uma fêmea de raça definida.

Há interação entre cães domiciliados e de raça definida. As duas variáveis têm um fator protetor em relação ao risco de contrair a infecção, e, quando estão relacionadas, o fator protetor aumenta, correspondendo a um risco de se infectar, de 1,035. Os cães capturados nas ruas, ou seja, cães sem donos e sem raça definida ou de proprietários relapsos, são a categoria com maior risco de se infectar: tem 3,59 vezes mais risco. Esse fato já foi citado anteriormente pelo hábito de o cão de rua andar em grupos quando fêmeas estão no cio. Além disso, pode-se considerar que o cão vadio não é vacinado contra leptospirose, bebe água empoçada, revira lixos com restos de alimentos contaminados com urina de roedores e, ocasionalmente, se envolve em brigas podendo ocorrer contaminação pela saliva, conforme citado por Veronesi et al. (1956).

Em relação à vacinação, em Belo Horizonte, a maioria dos produtos comerciais existentes hoje no mercado contém antígenos que imunizam contra as sorovariedades Icterohaemorrhagiae e Canicola (Hagiwara et al. (2004). A inclusão de novas sorovariedades em vacinas comerciais requer pesquisas de isolamento e identificação para comprovar os achados dos inquéritos sorológicos. Em Belo Horizonte, não existe, até o momento, vacina comercial que contenha as sorovariedades Ballum e Pyrogenes, encontradas como a segunda e a terceira mais prevalentes no município, respectivamente. Novas pesquisas devem ser realizadas com o objetivo de isolar e tipificar as sorovariedades em cães que apresentam respostas sorológicas para Ballum e Pyrogenes e assim acrescentá-las às vacinas comerciais contra leptospirose utilizadas em cães nesse município.

Palavras-chave: cão, Leptospira interrogans, prevalência

\begin{abstract}
The serological profile of seropositive dogs according to anti-Leptospira agglutinins was checked in Belo Horizonte including variables such as race, sex, age and whether the dog had an owner or not. The dogs were captured by the Zoonosis Control Center in nine neighborhoods around the city and were separated in two categories - with owners or captured on the streets. The prevalence of anti-Leptospira agglutinins
\end{abstract}


was evaluated in 3,417 blood samples using the microscopic agglutination test (MAT) from September 2001 to September 2002. It was found that 13.1\% of the dogs had seropositive results with the most reactive serovars being Canicola (7.0\%), Ballum (6.1\%), Pyrogenes (3.2\%) and Icterohaemorrhagiae $(2.9 \%)$. The prevalence of other serovars was less than $1.0 \%$. Greater prevalence was found in male, crossbred dogs, without owners. There were no significant results due to age in $95 \%(P=0.808)$ of the cases. According to the results, more research should be done in order to isolate and classify the serovars in positive dogs, especially Ballum and Pyrogenes, which will suggest their inclusion in the commercial vaccines against leptospira used in dogs in this city.

Keywords: dog, Leptospira interrogans, prevalence

\section{REFERÊNCIAS BIBLIOGRÁFICAS}

AGUIAR, D.M.; CAVALCANTE, G.T.; MARVULO, M.F.V. Fatores de risco associados à ocorrência de anticorpos anti-Leptospira spp. em cães do município de Monte Negro, Rondônia, Amazônia Ocidental Brasileira. Arq. Bras. Med. Vet. Zootec., v.59, p. 7076, 2007.

ÁVILA, F.A. et al. Freqüência de aglutininas antileptospira em cães do município de Jaboticabal, Brasil. In: ENCONTRO DE PESQUISAS VETERINÁRIAS, 5., 1980, Jaboticabal. Anais... Jaboticabal, 1980. p.68.

CALDAS, E.M.; DÓRIA, J.D. Inquérito sorológico para leptospirose em Canis familiares, na cidade de Salvador. In: CONGRESSO BRASILEIRO DE MEDICINA VETERINÁRIA, 15., 1976, Rio de Janeiro. Anais... Rio de Janeiro, 1976.

DEAN, A.G.; DEAN, J.A.; BURTON, A.J. et al. EPIINFO, a word processing, date base and statistis program for epidemiology on microcomputers. Version 6.02. Georgia: USD, 1995.

DOHOO, I.; MARTIN, W.; STRYHN, H. Veterinary epidemiologic research. Charlottetown: AVC, 2003. $706 \mathrm{p}$.

HAGIWARA, M.K.; SANTA ROSA, C.A. Leptospirose canina em São Paulo. Arq. Inst. Biol. São Paulo, v.42, p.111-118, 1975.

HAGIWARA, M.K; LUSTOSA, M; KOGIKA, M.M. Leptospirose Canina. Schering-Plough Coopers, 2004 ( Artigo técnico, 10).

LILEMBAUM, W.; RODRIGUES, F.; BARBOZA, F. Aglutininas antileptospiras em caninos do município amazônico de Oriximina-Pará, Brasil. Rev. Bras. Cienc. Vet., v.7, p.133-135, 2000.

MAGALHÃES, D.F.; SILVA J.A.; MOREIRA, E.C. Prevalência de aglutininas anti-Leptospira interrogans em cães de Belo Horizonte, Minas Gerais, 2001 a 2002. Arq. Bras. Med. Vet. Zootec., v.58, p.167-174, 2006.

MODOLO, J.R.; LANGONI, H.; SHIMABUKURU, $F$. et al. Inquérito soroepidemiológico para leptospirose canina no município de Botucatu, SP. In: CONGRESSO BRASILEIRO DE MEDICINA VETERINÁRIA DE CAMPO GRANDE, 26., 1999, Campo Grande. Anais... Campo Grande, 1999.

PROCEDIMIENTOS para estudios de prevalencia por muestreo. Buenos Aires: CEPANZO, 1979 (Nota técnica, 18).

REIS, R.; RYU, E.; MOPTA, J.G. et al. Pesquisa de aglutininas anti-leptospira em cães pelo teste da Microaglutinação Rápida. In: CONGRESSO BRASILEIRO DE MEDICINA VETERINÁRIA, 13., 1972, Brasília. Anais... Brasília, 1972. p.297.

ROSSETI, C.A.; ROMERO, G.N.; AUTERI, C.D. et al. Estudio serológico de leptospirosis em perros de partidos del Oeste del Gran Buenos Aires. Rev. Med. Vet., v.80, p.98-305, 1999.

RYU, E. Rapid microscopic agglutination test for leptospira without non-specific reaction. Bull. Off. Int. Epiz., v.73, p.49-58, 1970.

SAMPAIO, I.B.M. (Ed). Estatística aplicada à experimentação animal. Belo Horizonte: FEP-MVZ, 1998. 221p.

SANTA ROSA, C.A.; TERUYA, J.M.; YANGUITA, R.M. et al. Inquérito sorológico para leptospirose e brucelose em cães da cidade de Belo Horizonte. Arq. Esc. Vet. UFMG, v.26, p.339-342, 1974.

VERONESI, R.; NETO, V.A.; CORRÊA, M.O.A. Leptospiroses em cães da cidade de São Paulo. Inquérito sorológico. Rev. Inst. Adolfo Lutz, v.16, p.78-81, 1956. 